\title{
Jugar al caboco en el maracatú de Mata Norte en Pernambuco (Brasil)*
}

\author{
Playing caboco in maracatú of Mata Norte, Pernambuco (Brazil)
}

\author{
Noshua Amoras ** \\ Universidade Federal do Rio de Janeiro (UFRJ), Brasil
}

DOI: $10.22380 / 2539472 X .2017$

\begin{abstract}
RESUMEN
Este artículo analiza las figuras (personajes) del maracatú, un juego típico de la región de la Zona da Mata (zona forestal) pernambucana en Brasil, que data del periodo colonial y que moviliza planos míticos, poéticos y corporales. Mostraré que jugar al caboco, una de las figuras más emblemáticas del maracatú, implica tanto un cuidadoso procedimiento de ornamentación ritual como un aspecto menos visible, relacionado con las transformaciones corporales que emergen en los festejadores y que les permiten adquirir ciertas fuerzas y poderes. Dado que estos últimos se vinculan con el "tiempo antiguo" del juego — admirado y temido a la vez-, jugar al caboco envuelve un dilema para los festejadores: ¿cómo experimentar transformaciones corporales y vinculaciones con ciertas fuerzas sin dejar que estas los tomen por completo?
\end{abstract}

Palabras clave: Pernambuco, Zona da Mata, cultura popular, maracatú.

\begin{abstract}
This article analyzes the figuras (characters) of the maracatú, a typical play of the Pernambuco region of the Zona da Mata (forest zone) in Brazil, that dates back to the colonial period and which mobilizes mythical, poetic and corporal elements. I will demonstrate that playing caboco (a emblematic maracatu's figure) involves both a careful ritual ornamentation procedure and a less visible aspect, related to the bodily transformations that emerge in the players and that allow them to acquire certain strengths and powers. Given that the latter are linked to the "old time" of the play - admired and feared at the same time - playing caboco involves a dilemma for the players: how to experience bodily transformations and connections with certain forces without letting them take them over in full?
\end{abstract}

Keywords: Pernambuco, Zona da Mata, popular culture, maracatú.

\footnotetext{
* Este artículo es una derivación de reflexiones que iniciaron durante el pregrado y la maestría (Amoras 2015, 2018) y de un trabajo de campo de más de ocho meses entre 2014 y 2017. Agradezco la financiación para adelantar la investigación que recibí del Departamento de Antropología de la Universidade de Brasilia y de la Coordenação de Aperfeiçoamento de Pessoa de Nível Superior (Capes). Así mismo, a los festejadores por los diálogos y la convivencia durante estos años. Finalmente, agradezco los valiosos comentarios y las lecturas atentas de Bárbara Cruz y Helena Assunção. Traducción de América Larraín González (Universidad Nacional de Colombia, sede Medellín).

La RCA agradece al autor y a la revista Hawò haber permitido su traducción al español para este número especial [N. del E.]

** noshua.amoras@gmail.com / https://orcid.org/0000-0003-2955-9230
} 


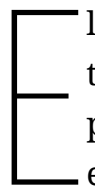

l maracatú es un juego presente en la Zona da Mata (área forestal), al norte de Pernambuco, una región brasileña mayoritariamente caracterizada por las plantaciones de caña de azúcar desde el periodo colonial o desde el "tiempo antiguo" - para usar una expresión local—. Tal como expuse en un trabajo previo (Amoras 2015) y como muestra Acselrad (2019), en las narrativas locales se argumenta que juegos como el maracatú, los caboclinhos y el cavalo marim fueron creados en los ingenios azucareros, y se destaca su carácter agnóstico estructural en planos míticos, poéticos y corporales que conciernen también a los peligros de los juegos. La afirmación "Estamos jugando aquí. Es en serio” condensa la atmósfera creada por el maracatú.

El carnaval es uno de los principales periodos en que los festejadores (hombres, mujeres, jóvenes, adultos y ancianos que juegan maracatú) visten sus trajes y samban - haciendo maniobras y "evoluciones"- como baianas (bahianas), indias, cazadores, burras, mateus, catita, arreiamás o cabocos ${ }^{1}$. Esas figuras (personajes) corresponden a un conjunto más o menos fijo que sale de las sedes de los maracatús los domingos de carnaval y se presenta en las calles de Mata Norte y de Recife hasta el martes siguiente. Cada uno de esos tipos tiene una vestimenta y una performance únicas alusivas a su grupo.

Por ejemplo, los cabocos visten grandes túnicas bordadas con lentejuelas y cuentas que les cubren de los hombros a los pies, y portan las guiadas, bastones de madera de casi dos metros de altura decorados con cintas de tela, utilizados tanto en sus maniobras (performances coreográficas) como para golpear (embates físicos entre dos o más cabocos). En la cabeza lucen sombreros coloridos y en la espalda cargan zurrones o sonajeros, un pesado conjunto de campanas que indican desde lejos que hay un caboco en los alrededores, bien sea solo o en pequeños grupos.

En ese sentido, las expresiones más frecuentes para referirse a quien viste una figura son: "está jugando al caboco", "ese es un buen caboco”, "ella salió como bahiana”, "ella es bahiana en el maracatú”. Es decir, todos esos términos (ser, jugar, salir) indican de manera general el acto de una persona que se viste de determinada figura y realiza la performance esperada. Así, en buena parte, el maracatú puede definirse por su aspecto más visual.

En general, la literatura antropológica ha prestado poca atención a las figuras de los juegos de Mata Norte - así como a otras presentes en Pernambuco y alrededores - . Por esta razón, rara vez se piensa un estatuto propio para ellas. No está de más decir que los análisis se han limitado a describir las características

1 Caboco o caboclo es una palabra en portugués que designa de modo general a un mestizo y que puede ser usada peyorativamente para descalificar. [N. de la T.] 
estéticas más visibles de las figuras y a especular sobre lo que representan —en la historia o en la sociedad-por medio de la idea de identidad. Así, en el caso del maracatú, se presume que, vistiéndose de cabocos, los festejadores representarían que de hecho son cabocos - es decir, descendientes de negros o indígenas - (Assis 1997; A. Silva 2016; Garrabé 2010; Medeiros 2005; Murphy 2008; S. Silva 2005). Sin embargo, intentar descubrir las representaciones sociales e históricas evocadas por las figuras no me parece muy provechoso, pues los análisis de ese tipo se basan en causalidades o simples continuidades entre un plano que sería "más real" (el contexto histórico, social, económico, por ejemplo) y otro “menos real” (el juego).

El desafío que este artículo aborda, por lo tanto, es el de buscar una manera de describir y entender las figuras del maracatú sin recurrir a una perspectiva simbólica o performativa. De esta forma, doy continuidad a las reflexiones iniciadas en contextos semejantes — como el del cavalo marim (Acselrad 2013; Teixeira 2013; Tenderini 2003)—, donde las figuras son pensadas como "otros dentro de un solo yo" y revelan la multiplicidad de subjetividades de los festejadores (Acselrad 2013, 138-139).

Para avanzar con este argumento y atender al funcionamiento de esa multiplicidad, abordaré el caboco como figura emblemática del maracatú. La decisión se justifica por la centralidad de esta figura en el juego. Tomando en cuenta la amplitud de significados que el término tiene en antropología, adquiere contornos específicos en este contexto. Así, el caboco resulta ser una especie de metonimia del maracatú, considerando que en el llamado tiempo antiguo el juego no se estratificaba en grupos bien definidos, como ocurre hoy, sino que se entendía como sinónimo de "andar por el mundo"; es decir: caboco es maracatú y el maracatú implica transitar.

Si bien la figura del caboco se caracteriza primeramente por los accesorios singulares descritos, no se limita a ellos. Se afirma que los grandes festejadores, aquellos que juegan como se hacía antiguamente, no requieren estar vestidos con sus disfraces para ser cabocos porque, según veremos, ellos mismos son cabocos ${ }^{2}$. Para argumentar esto, me baso en una etnografía realizada junto a los festejadores del maracatú Leão de Ouro, con sede en la ciudad de Condado, cuyo dueño es Severino Alexandre ${ }^{3}$. Este grupo está compuesto por una red de festejadores de

2 Según se verá a lo largo del texto, los términos festejador (folgazão) y caboco pueden aparecer como equivalentes en algunos contextos, pues los interlocutores se alternan para usarlos. Mostraré que esto se relaciona con la propia constitución de la figura de maracatú.

3 Severino Alexandre es además dueño de Cavalo Marinho Estrela de Ouro, donde también participan sus descendientes. Cavalo marim y maracatú integran el mismo complejo de juegos de Mata Norte, pero la relación entre ellos es particularmente estrecha en el caso de esa familia, pues los juegos comparten festejadores y sede, lo que no necesariamente ocurre en otros lugares. 
Condado y municipios vecinos, muchas veces unidos por relaciones de parentesco, compadrazgo y vecindad. Así, aunque los hijos, nietos y bisnietos de Severino Alexandre juegan en el maracatú, también lo hacen vecinos, conocidos y residentes de otros lugares. La cantidad de personas que participa allí va entre menos de doce en el transcurso del año hasta más de cien en tiempos de carnaval. El maracatú, en cuanto grupo que sale en el periodo de carnaval, es apenas uno de los aspectos del maracatú como juego que continúa existiendo en el transcurso del año, bien sea en momentos destacados, como sambadas y ensayos, o en las conversaciones de los festejadores, en sus comportamientos y en sus prácticas cotidianas.

El propósito de este artículo es abordar las figuras del maracatú, centrándonos en el caboco. Para ello, mostraré que jugar al caboco implica tanto un cuidadoso procedimiento de ornamentación ritual como un aspecto menos visible: las transformaciones corporales que emergen cuando los festejadores juegan y que les permiten la adquisición de ciertas fuerzas y poderes. Esas fuerzas y poderes están asociados al tiempo antiguo del juego, el cual es tan admirado como temido. En ese sentido, jugar al caboco envuelve un dilema con el que los festejadores se enfrentan: ¿cómo experimentar transformaciones corporales y vínculos con ciertas fuerzas sin dejar que estas se apoderen completamente de ellos? Lo que veremos entonces es en qué consiste, desde el punto de vista de los festejadores, jugar al caboco en el maracatú.

\section{El caboco y su ornamentación}

Antes de dejar la sede y salir al carnaval, en el maracatú cada caboco hace su llegada. Las llegadas son una especie de presentación y se hacen una tras otra: a medida que los cabocos arriban a la sede, el público abre espacio en la calle para que ellos las realicen. Uno de los objetivos de la llegada es que el caboco muestre su belleza y habilidad al público.

El caboco se adentra en el espacio haciendo sus maniobras al ritmo del golpe del terno (el conjunto musical) y enseguida arrea los pies del maestro invitándolo a cantar sus loas. El maestro anuncia el nombre del caboco y hace comentarios elogiosos sobre él. Al concluir, el caboco termina su maniobra y le da la entrada a la siguiente llegada. Finalmente, todas las figuras del maracatú se reúnen y maniobran frente a la sede para dar apertura a los tres días de carnaval hasta el Miércoles de Ceniza. Me gustaría destacar que, a partir de ese momento 
y hasta el final del carnaval, el festejador casi nunca será llamado por su nombre propio. Es decir que, después de su llegada, pasará simplemente a ser un caboco. Sin embargo, se puede decir que el carnaval inicia antes de la llegada, cuando el festejador se viste de caboco, es decir, cuando se pone la ornamentación, que es un proceso lento y demorado. Primero va la fofa, un tipo de pantalón, y después la camisa; luego se amarra un pañuelo en la cabeza, se cuelga el zurrón (sonajero) en la espalda — de modo tal que quede bien adherido al cuerpo-, se pone la túnica decorada sobre los hombros dejándola caer hasta los pies y, enseguida, se coloca el sombrero; después se pinta el rostro de rojo, pone un clavel en su boca y toma agua de sus manos; y, por las dudas, se persigna al terminar.

Cada caboco de maracatú posee una ornamentación propia. Aunque de manera general haya un mismo formato, no siguen un patrón idéntico de motivos, colores o tamaños; de hecho, aunque exista un estilo que varía según la región, cada caboco compone su propio traje con el objetivo de producir el atuendo más bonito y decorado. Por otro lado, aquellos que solo salen esporádicamente en maracatús suelen tomar prestados los ornamentos de sus respectivas sedes, confeccionados para que los participantes ocasionales los usen y los devuelvan el mismo día. Esto no siempre es bien visto por los festejadores, que pueden considerarlos vestuarios muy gastados y “que cualquiera usa”. En contraste, aquellos que se dedican a producir sus propios trajes y ornamentos cada año suelen ser considerados cabocos bien preparados.

La ornamentación consiste en diversos objetos que en sí mismos son bastante pesados; sin embargo, es común que suela verse muy bien, incluso ligera, cuando el festejador la usa. Gracias a esta apariencia, los cabocos consiguen lanzar sus bastones hacia lo alto y agarrarlos de vuelta, además de andar con sus zurrones por largas distancias sin cansarse.

Un caboco bien preparado vestirá su traje apenas unos instantes antes de la salida del maracatú. Las túnicas, los sombreros y los bastones utilizados a lo largo del año serán los del carnaval anterior: nada nuevo se incluye cuando, por algún motivo, el maracatú se presenta en teatros, festivales, etc. Durante los meses previos al carnaval, buena parte de los festejadores está confeccionando sus túnicas y atando las cintas en sus bastones, además de haber escogido los nuevos colores de su sombrero. Algunos, incluso, les ponen nuevas campanas a sus zurrones. Quizá por la sospecha de una posible envidia, se recomienda hacer todo esto en casa y en secreto, lejos de los ojos curiosos de los vecinos. Es común oír comentarios de reprobación a quien toma fotos de sus túnicas o las confecciona en lugares muy públicos - lo cual no impide que ocurra con cierta frecuencia-. Ese cuidado se extiende a los otros objetos y ropas del maracatú, como la bandera del grupo y los vestidos de las bahianas. 
Don Ramiro es un famoso caboco de maracatú y por mucho tiempo estuvo al frente del grupo del Leão de Ouro como mestre caboco, liderando las maniobras y “evoluciones” de ese maracatú. Él habla sobre los cuidados de su ornamentación que, desde la compra de los materiales hasta los últimos detalles de la confección, es producida exclusivamente por él y su familia:

Nadie ve mi túnica antes del día indicado. El estandarte del maracatú tampoco debe ser visto, menos por maestros de otros maracatús. Un día, mi mujer estaba haciendo mi túnica y llegó un señor; cuando ella lo vio, cubrió la tela. Entonces él le preguntó: “¿De quién es esa túnica?”, y mi mujer le respondió "Del muchacho tal”, para despistarlo. Después, él fue a la casa de mi suegra, que no sabía nada, y le preguntó también por la túnica. Ella le confirmó que era mía. Al día siguiente, el señor trajo una tela nueva y marcada, y se la entregó a mi mujer para que se la decorara. Yo ni toqué la tela porque sospechaba que él la había llevado a un catimbozeiro (curandero/hechicero); mi hija la agarró, la dobló, la puso en una bolsa y la botó. Faltaban dos meses para el carnaval. (Ramiro, agosto de 2014)

Son frecuentes las narrativas que aluden a los minuciosos cuidados que deben tomarse durante la preparación para el carnaval. Eso implica, por ejemplo, confeccionar esos objetos lejos de ojos curiosos o envidiosos, pero también estar atento a posibles hechizos que puedan causar una caída del caboco, su desorientación o una enfermedad. De esta forma, don Ramiro indica que ser un caboco bien preparado no significa solamente usar las ropas más bonitas, es decir, no se limita a una dimensión estética. Además de la túnica, otro elemento de la ornamentación es el zurrón o sonajero que se carga en la espalda, el cual emite un sonido alto cuando el caboco camina y anuncia su presencia a metros de distancia. Sin embargo, algunos zurrones emiten sonidos bajos, roncos, debido a que sus dueños "no buscaron su sonido"4.

El zurrón es quizá el objeto que mejor contiene los misterios del caboco, razón por la cual, a pesar de su aparente peso, solamente su dueño y eventualmente sus hijos consiguen manejarlo con facilidad. Cuando un festejador interrumpe definitivamente su juego, suele dejar su zurrón recostado, colgando en el tope del tejado de su casa o guardado en un lugar de su residencia. Al zurrón se le escucha hacer ruido desde donde sea y sin la intervención de nadie. Se trata de un fenómeno poco extraordinario y sobre el cual se habla con relativa normalidad. João Pererê, famoso caboco de la ciudad, contó que cuando era niño oyó algunas veces

$4 \quad$ Este no es un asunto sobre el cual los festejadores hablen con frecuencia. Cuando oí acerca de "buscar el sonido", las personas hacían referencia a que los festejadores debían dirigirse a un lugar específico, entrar en un embate con un ser similar a un caboco de maracatú y regresar victoriosos. 
el zurrón de su padre hacer ruido por sí solo. Incluso su propio zurrón comenzó a hacer lo mismo cuando él paró de jugar:

Muchas veces ocurre, cuando pasas mucho tiempo sin jugar... Las mías [refiriéndose a las campanas] ya han sonado algunas veces. Un día puse mi zurrón recostado en la pared y se movió solo. Entonces, mis hijos se dieron cuenta... dijeron que mi zurrón tenía algo... A veces mi hijo lo agarra y lo hace sonar. Cuando yo era pequeño, el zurrón de mi papá estaba colgado en la pared — antes se cubrían con piel de cabra, ahora son más bonitos-. Yo miraba a mi papá que lo pintaba de rojo y, de repente, el zurrón empezó a sonar. Entonces, sorprendido, le dije: "Papá, tu zurrón está sonando”, y él me respondió: “Tranquilo, hijo, no pasa nada...”. (João Pererê, agosto de 2014)

“Eso no es nuevo”, me dijo una vez doña Bibi, quien está relacionada con los juegos de la región desde la infancia por haber visto a su padre jugar y por acompañar anualmente las llegadas de su marido, un caboco conocido en la región. Doña Bibi aludía a la recurrencia de este fenómeno, pero también a las raras ocasiones en que estos objetos se guardaban en casa, y explicó que no era costumbre que la ornamentación del maracatú "se convirtiera en una herencia” para ser usada por alguien distinto a su dueño o que se guardara sin intención de jugar; estas son prácticas recientes. Antiguamente, al final del carnaval, las ornamentaciones solían quemarse frente a las sedes de maracatú. Sin embargo, parece que hoy nadie más quema su traje - por lo menos frente a las sedes - y lo más común es deshacerse de él en caso de fallecimiento. Cuando se interrumpe definitivamente el movimiento del caboco, se debe dar fin también a su ropa: antes "no quedaba herencia”, destacó doña Bibi con énfasis y añadió que "se enterraba todo; se enterraba o se quemaba”.

Si la ornamentación se mantiene "viva” y tiende a ejercer su fuerza aun cuando el juego se ha detenido, ¿qué puede hacer un festejador cuando quiere o necesita dejar de jugar definitivamente? Hasta donde pude percibir, cuando un festejador deja de jugar por un periodo - y de alguna forma presiente que puede retornar-, vende su ropa o la deja guardada hasta que pueda retomar el juego. Mientras tanto, a pesar de que el festejador esté detenido, la ropa seguirá en movimiento, por ejemplo, en el cuerpo de otro festejador o en el zurrón haciendo ruido solo. De hecho, un festejador se alegra mucho cuando compra la ornamentación de alguien considerado un buen caboco. 
Pero ¿qué ocurre cuando el festejador abandona el juego por “molestia”, por nuevas creencias religiosas ${ }^{5}$ o porque fallece? En esos casos, la ropa debe ser destruida. Cuando no se realiza la destrucción definitiva de la ropa, en cierta medida sigue existiendo, en el sentido de que tanto ella como su fallecido dueño pueden espantar a los familiares del festejador. En la siguiente narrativa, un señor que jugaba como burra (otra figura del maracatú) especificó el destino que quería que tuviera su ornamentación después de su muerte:

Mi papá jugaba en la burra. Le ponía un lazo, la arreglaba, le hacía vestido y todo. Cuando era sábado de carnaval, iba bien temprano al río de Agua Limpia a tomar un baño con jabón amarillo. Llegaba a casa y le ponía ropa a la burra. Daba tres relinchos, arrodillado en el piso y después iba hacia la ventana. Nadie se hacía frente al espejo porque podría traer mala suerte. Él, su madre o su padre podrían morir. Se iba y regresaba el miércoles. Relinchaba fuerte los miércoles. Mi mamá decía “Llegó tu papá”, ella abría la puerta, ponía una vela en la esquina de la pared, él iba para un lado y para otro relinchando; se arrodillaba al pie de la vela y se quitaba todo. De madrugada se iba a trabajar. Jugaba solo en medio del mundo. Jugaba porque sabía jugar. Cuando él murió, quedó su burra. Él murió en Paraíba y nos había pedido que pusiéramos la burra y la ropa, todo en su féretro. Yo le dije: "Papá, no tengo cómo ir a Paraíba cuando mueras. Tienes que avisarme y entierro las cosas donde tú me digas”. Cuando murió, se me apareció y me preguntó: “Dónde están mi ropa y la cabeza de mi burra? Entierra todo al mediodía en el cruce de caminos”. Entonces fui y lo enterré. Cuando ya había regresado a casa, él me lanzó una piedra en el tobillo. Le dije: “¿Fuiste tú, papá?”. ¡Él me agradeció lanzándome una piedra! [risas]. (Agosto de 2014)

Una figura se define por sus ropas y objetos característicos. Así, un caboco no puede usar un sombrero de arreiamá ${ }^{6}$ en lugar del suyo o el pequeño bastón de mateus $^{7}$ en lugar del propio. Ese tipo de mezcla sería impensable para

$5 \quad$ El maracatú no está necesariamente vinculado o circunscrito a una religión. Los festejadores se reconocen como católicos y muchos también practican y frecuentan religiones de matriz africana - como por ejemplo, xangô, umbanda, jurema y catimbó-. Hay una movilidad religiosa entre las personas. Sin embargo, la conversión a las religiones evangélicas impide hacer parte de los juegos.

Ocasionalmente, la figura que usa este sombrero es llamada caboco de pena. También hay registros bajo el nombre de tuxauas o tuchauás (Oliveira 1948). Usan túnicas con bordados más simples, cargan un machetico en las manos y llevan en la cabeza un gran sombrero hecho de plumas de pavo real. Su performance consiste en movimientos corporales extremadamente rápidos y habilidosos. En la Zona da Mata, hay comparsas de carnaval llamadas tribos de índios que fueron numerosas en el pasado e incluyen varias de esas figuras.

7 La mención a la figura de mateus puede ser encontrada en juegos de diferentes regiones de Brasil. En todas, actúa como un tipo de trickster o pícaro divino, frecuentemente con una 
los festejadores que probablemente dirían que ni siquiera se trata de un maracatú. Además de eso, como vimos, esos objetos deben ser cuidadosamente creados, trabajados, usados e incluso destruidos, por la estrecha relación entre las ornamentaciones y sus dueños. En ese sentido, los accesorios de la ornamentación de un caboco no son simplemente vestimentas que cubren el cuerpo. Constatar el estatuto de esos objetos va más allá de afirmar que poseen agencia o que se constituyen mutuamente con los festejadores. Aunque esto sea cierto, no es suficiente para comprender la complejidad que compone una figura de maracatú. "Jugaba porque sabía jugar”, dijo la señora que contó la historia de su padre. Así, además de la constatación elogiosa sobre lo bueno que era el padre jugando como burra —su performance, digamos-, saber jugar implica otras capacidades.

\section{Transformaciones corporales $y$ adquisición de fuerza}

Desde los primeros registros del maracatú (Bastide 1945; Ferreira 1951; Freyre 1968), se ha especulado acerca de la existencia de esos seres avistados en medio de los cañaduzales o calles de las ciudades, cubiertos con una ropa llena de lentejuelas coloridas y cintas relucientes, que cargan un bastón de madera para usar en enfrentamientos. Se especula también acerca de aquello que posibilitaría las hazañas extraordinarias ampliamente narradas por los festejadores, especialmente sobre sus antepasados.

Sobre esto, es común encontrar dos hipótesis. Una explica las capacidades de los cabocos a partir de las relaciones de los festejadores con religiones de matriz africana y afrobrasileña: jugar al caboco, según esta explicación, implicaría ser poseído por alguna entidad espiritual (ver Bonald Neto 1991; Omim 2008; Real 1967). Otra hipótesis recurrente es la ingestión de sustancias psicotrópicas, más específicamente el azougue (bebida hecha con pólvora, aguardiente y limón), que los festejadores tomarían durante los días de carnaval. Como argumenta Estrada $(2015,131)$, la imagen del azougue continúa influenciando las representaciones del maracatú actualmente. Así, la literatura sobre el tema se refiere a ello como una posible fuente para alcanzar estados de consciencia alterada (Assis

performance cómica. En el caso del maracatú, parece que viste versiones más pequeñas de los accesorios del caboco: un sombrerito, una túnica pequeña y un bastoncito. 
1997; Estrada 2015; Garrabé 2010; Vieira 2012). Sin embargo, según los mismos estudios, esa práctica estaría en desuso en la actualidad.

En un contexto etnográfico distinto, Marilyn Strathern (2013, 26-28) resalta que la ideología euroamericana comprende el acto de decorarse para situaciones rituales como una representación, de manera que los cuerpos decorados revelarían el contexto social más amplio y funcionarían como vehículos de información que ejercen papeles sociales. Sin embargo, según muestra la autora, esos actos implican un juego mucho más complejo de hacerse y transformarse, de ocultar y revelar las relaciones. Si el cuerpo está siendo ocultado por objetos y decoraciones, la persona a su vez es representada como el nexo de relaciones. De esta forma, máscaras, pinturas y ornamentos rituales - al menos en el caso melanesio que documenta Strathern-operan como una especie de juego de fondo y forma entre interior y exterior; y, más que ocultar un cuerpo, hacen visibles las relaciones que antes eran internas, domésticas y ocultas (46-48).

El problema con las dos hipótesis presentadas en la bibliografía sobre el maracatú es que ambas condicionan las experiencias de los festejadores a explicaciones y motivaciones externas. Algunas personas que juegan maracatú frecuentan centros religiosos de matriz afro y no consideran la experiencia del juego en analogía o proximidad con la de posesión; por esta razón, creo que les parecería extraña la idea de que jugar al caboco implica necesariamente la presencia de divinidades y entidades como condición para las transformaciones en las cuales se encuentran implicadas ${ }^{8}$. Y aunque entidades espirituales y sustancias como el azougue eventualmente estén presentes en el juego, suelen ser menos importantes que aquello que las antecede. Tomando en cuenta la propuesta de Strathern (2013), quien afirma que ornamentarse implica evidenciar, hacer visibles ciertas relaciones, mi hipótesis es que en el acto del juego son producidas y obtenidas distintas fuerzas, características y relaciones. A diferencia de la interpretación externalista — según la cual son las cosas externas las que permitirían las hazañas extraordinarias-, algo que ya está allí de manera latente es producido y externalizado en unos nuevos términos. Veamos esto con detenimiento.

Es común oír comentarios de los festejadores sobre sí mismos y sobre sus colegas en los que resaltan que sus expresiones faciales se transforman y se hacen "diferentes” cuando juegan maracatú. Algunos llegan a decir que no recuerdan ciertos eventos cuando están jugando. Derivan, un joven caboco de Leão de Ouro que se enfermó pocos días antes de un carnaval, mejoró de repente justo

8 Este punto no será tratado con la profundidad que merece, pues requiere una reflexión más cuidadosa que no es posible en los límites de este artículo. Por ahora, enfatizo que el ejercicio consiste en dar un estatuto propio a la experiencia de jugar al caboco. 
el día de la salida del maracatú y hasta el Miércoles de Ceniza. "Misterio del carnaval”, sentenció él. Los festejadores afirman que suelen ser evidentes distintos cambios en sus semblantes y comportamientos; según ellos, se vuelven más serios, introspectivos y poco dados a intercambiar palabras con otras personas. Algunos, incluso, llegan a tornarse irreconocibles.

Como vimos, aun cuando los objetos que caracterizan las figuras son fabricados y utilizados con cierto cuidado e incluso son partes destacables constitutivas de los festejadores, el disfraz de un caboco y sus objetos no son simples envoltorios sobre el cuerpo. Al contrario, son complementos de la persona y eventualmente traen a la vista trazos de ella misma (gestos, expresiones faciales y otros aspectos físicos). João Pererê habla de cuando acostumbraba a vestir su ornamentación para jugar maracatú e indica la complejidad de ese proceso:

Antiguamente se usaba azarcón. Cuando estábamos vistiéndonos, empezábamos a pintarnos y al poco tiempo teníamos los ojos hundidos. Era... cuando se unta el azarcón se transforma a la persona, era de ese mismo color, rojo. Si se pintaba todo, se hundían los ojos. Nadie podía reconocerte y empezaba a temblarte el rostro. Entonces, el caboco salía a andar y el azarcón no salía durante tres días. Hoy con labial es otra $\operatorname{cosa}^{9}$. (João Pererê, agosto de 2014)

Esta descripción demuestra que disfrazarse posibilita una transformación de sí mismo, uno de cuyos efectos es que nadie conozca al festejador. Eso quiere decir que, en su caso, cuando alguien viera al caboco João Pererê, difícilmente conseguiría enfocar bien su rostro para reconocer a la persona tras él. Pero, más que eso, significa que nadie podría siquiera conocer a aquel ser como João Pererê.

Ciertos periodos del maracatú propician situaciones como la narrada por el festejador. Además del carnaval, existe el maracatú de Semana Santa, usualmente considerado como el más peligroso. En esta ocasión, no es el juego, como agremiación carnavalesca, el que sale a la calle, sino los cabocos invocados por el deseo de "andar por el mundo". La consideración de los maracatús de Semana Santa como peligrosos deriva de los enfrentamientos que normalmente no sucederían en otras ocasiones y que sí toman lugar en esa época, al igual que ocurre en los encuentros con el diablo, con los espíritus, con cabocos que murieron, entre otros seres. Un festejador que resolvió salir en estas fechas por presión de sus amigos señaló que, "si hubiera sido por él”, no lo habría hecho. Decidió ponerse su zurrón y salir a andar por los alrededores. En una de las calles se encontró

9 Todo caboco de maracatú se pinta el rostro de rojo. Como dijo João Pererê, hoy normalmente se utiliza labial, pero antiguamente se usaban sustancias como el azarcón. 
con tres cabocos que, cerrándole el paso, lo conminaron a dar la vuelta por otra vía. Luego de negarse a seguir las instrucciones, el festejador percibió que uno de ellos era nada menos que su propio hermano. De repente, ambos comenzaron a golpearse y a empujarse hacia el borde de la calle. Los compañeros decidieron llamar a su madre, quien al final logró terminar el enfrentamiento. Como se acostumbra a decir, ellos se habían estranhado (desconocido).

Conocer y ser conocido, igual que desconocer, muestran que al cambiar - es decir, al jugar - los festejadores se convierten en algo ligeramente diferente de sí mismos. En cierta medida, todos sabían que aquel era João Pererê y cualquiera podría haber identificado al festejador que salió en Semana Santa, pero sabían también que aquellos seres no eran exactamente tales personas —eran cabocos - y que, además, un caboco de maracatú puede olvidarse de la familia cuando juega. Esto indicaría no solo la dedicación de un festejador hacia el juego, que puede ser igual o mayor a la que tiene por la familia, sino que las propias relaciones de parentesco son desconocidas o momentáneamente olvidadas. Así, es normal que un caboco no consiga discernir entre aquellos que puede o no enfrentar.

Es ajena a los festejadores, por tanto, la idea de que el maracatú sea pacífico o que un caboco sea simpático. Como ya fue mencionado con mayor énfasis en trabajos anteriores (Amoras 2015, 2018), hay cierto sentido bélico que impregna las diversas dimensiones del maracatú y les da un carácter agonístico. Una de estas dimensiones es que los enfrentamientos entre cabocos se expresan en una idea territorial. Por ejemplo, no suele esperarse que eviten a alguien o algo que se cruza en su camino: el caboco "sai atropellando" (sale atropellando). Usualmente, la llegada de un caboco a un espacio previamente ocupado por otro implica un momento de tensión. Dos cosas pueden ocurrir: el recién llegado se desvía (mostrando miedo) o ambos deciden convertirse en antagonistas para comenzar a agredirse. Esto funciona también en los grupos de maracatú: “¿Dónde se ha visto un [grupo de] maracatú que pase en medio de otro?”, me dijo don Ramiro al explicar que un grupo no debe alejarse para dar paso a otro.

Se trata de un juego permeado de peligros que se expresan en distintos niveles: desde disputas en el certamen del carnaval de Recife hasta ataques y contraataques con hechizos. Esto exige que las personas tengan cuidado y estén preparadas frente a la inminencia de ataques visibles e invisibles de los cuales pueden ser objeto. Por eso, los maracatús y los cabocos están siempre manejando técnicas que brinden protección y fuerza para jugar en el carnaval y garanticen el éxito, la destreza y la habilidad. Tales prácticas son variadas y no hacen parte de un único conjunto. 
En ese aspecto, los festejadores son fundamentalmente creativos y enfatizan la necesidad de que cada uno tenga un modo de protección y producción de fuerza que no debe ser compartido con otras personas. Son comunes, entonces, las menciones al uso de preparaciones, baños, rezos, pactos o incluso catimbozeiros $^{10}$ antes del carnaval, con el objetivo de "cerrar" el cuerpo, hacer amuletos $^{11}$, dejar el cuerpo protegido o - dicen algunos - confundir y molestar a los antagonistas. Pero, en general, el objetivo explícito es posibilitar a los cabocos el aumento de resistencia, fuerza, mandinga, etc. Quienes hacen estas revelaciones generalmente afirman no necesitar esa clase de recursos, pero dicen también que quien los usa consigue, por ejemplo, moverse inusualmente rápido o incluso hacerse invisible.

Acceder a tales técnicas es considerado algo más común y recurrente en el tiempo antiguo del juego. Una de las más evocadas se refiere a los pactos que garantizarían que cada año el caboco saliera seguro y poderoso durante el carnaval. Tales pactos eran hechos con seres ${ }^{12}$, entre los cuales se destaca el diablo:

Fulano hizo un trato con el diablo para poder jugar durante veintiún años. Él quiso jugar un año más y no lo logró. Ese año llegó un tipo —el diablo- preguntándole si iba a jugar y después se esfumó. Eran las ocho, el hombre entró a su casa, salió para jugar y no regresó. Amaneció un miércoles en Timbaúba. Se la pasaba en bares y ferias; estaba loco. Llegó el carnaval del año siguiente y todo el mundo jugó. Su hermano anduvo tres meses por el mundo con su zurrón. Estaba callado y así se quedó. Duró un año vivo y después murió. (Martelo, agosto de 2014).

Eran cabocos antiguos los que tenían el coraje de establecer relaciones con esos seres para hacer de ellos otra fuente de sus capacidades. El padre de don Ramiro era conocido como un caboco muy bueno y contra quien nadie ganaba un enfrentamiento. Eso ocurría porque — dice don Ramiro- él siempre llevaba a san Cipriano y santo Heleno cerca de sí para que le garantizaran el cuerpo cerrado. El problema - resalta el hijo del festejador - es que el uso excesivo de esas prácticas tiene efectos colaterales. Por ejemplo, un compromiso exagerado

10 El término catimbó puede ser encontrado en diversas regiones del estado de Pernambuco. En Mata Norte remite a prácticas que producen sortilegios, a religiones de matriz africana —como umbanda y jurema - y a técnicas de manipulación de sustancias curativas y de protección.

11 Se pueden hacer amuletos del propio cuerpo - y "cerrarlo" - o también de algún objeto que será cargado cerca de sí, como un collar o pulsera. El objeto servirá como una especie de talismán para la persona e impedirá que sea víctima de cualquier maleficio. Sobre más prácticas de protección y cuidado, ver Teixeira (2016).

12 Se dice que, en el tiempo antiguo, seres diversos habitaban la región, como la comadre fulorzinha, hechiceros, curupira y animales hablantes. Hoy, esos seres difícilmente son vistos en la región o perdieron las capacidades que antaño tenían. 
en esas relaciones hace que las personas no consigan mantener posesiones económicas: "Él no tenía nada, todo lo que tenía no sumaba kilo y medio. Nada. ¿Lo entiendes?”. Los festejadores que consiguen realizar bien ese cúmulo de fuerzas obtienen las ventajas deseadas y se consolidan como cabocos famosos - como el que hizo pacto con el diablo y logró jugar por tantos años-. Pero aquellos que no lo logran no pueden escapar de los efectos colaterales - como en el caso del festejador que enloqueció al romper el pacto que había hecho-. El padre de don Ramiro se mantuvo seguro en las décadas que jugó, pero, en contraprestación, nunca logró mantener posesión alguna.

Roy Wagner (1972) plantea la noción de impersonificación (inpersonation) para comprender la relación que los daribi de Papúa Nueva Guinea establecen entre los dominios humano y espiritual. Esa relación ocurre al "asumir la identidad de un ser, no exclusivamente al asumir su nombre, sino al adoptar su apariencia, mimetizando sus maneras y, en general, comprometiendo, en una forma imitativa, aspectos culturalmente significativos de su papel” (9). Tales formas imitativas no consisten en la correspondencia exacta entre dos seres, sino en la diferencia que se obtiene por la relación establecida. Es esa “metáfora de 'ser' humano y fantasma, o humano y dios, al mismo tiempo, [la que] permite la práctica de relaciones de poder esotérico en términos puramente sociales” (172).

La efectividad de la impersonificación depende directamente de cómo los atributos de un dominio son asumidos por los humanos; es decir, de cómo son transformados en capacidades humanas - lo que por sí solo cambia el propio dominio de lo que es considerado humano-. Dicho de otro modo, la persona se convierte en otra sin dejar de ser ella misma. En el sentido de la metáfora wagneriana, al mismo tiempo que un daribi es un fantasma, no puede serlo completamente. El "poder esotérico en términos puramente sociales" consiste — concluye Wagner - en la innovación adecuada, cuando imprime su "estilo" a quien lo recibe - estilo que retiene sentido apenas en la manutención del contraste entre los dominios - . De lo contrario, "si de hecho tal transformación [total] fuera a ocurrir, la metáfora sería colapsada en una equivalencia, y entonces el enlace mediador entre humano y espíritu estaría perdido y la ceremonia se tornaría inútil” (Wagner 1972, 173).

El estilo se convierte, más que en una innovación, en una forma de poder que pasa a ser constitutiva de la persona. Como se hará más evidente en la próxima y última sección de este texto, es del peligro que el maracatú deriva su fuerza. Aquí mostraré que un caboco de maracatú es aquel que experimenta transformaciones y cambios como los descritos, pero que, sin embargo, solo los considerados buenos festejadores son capaces de hacerlo de manera apropiada. 
En otras palabras, solamente los buenos transforman esos poderes esotéricos en un "estilo" propio, sin que eso implique que sean tomados completamente por tales poderes o que se establezcan equivalencias excesivas. Esto significa que dichos festejadores llevan hasta el límite las transformaciones corporales implicadas en el acto de jugar como caboco evitando los riesgos inherentes a ellas, es decir, los llamados desmantelos.

\section{El desmantelo y el peligro de ser otro}

Los cabocos de maracatú son conocidos - y muchas veces temidos- por su bravura, severidad y capacidad de actos que normalmente serían considerados imposibles: bastones que se transforman en serpientes, saltos que alcanzan diez metros de altura y movimientos tan rápidos que se tornan invisibles a los ojos. Sobre estos actos extraordinarios, doña Bibi me dijo alguna vez: "No, eso no es nada para el maracatú”. Con esto señalaba que todo lo que vemos hoy es poco si se compara con aquello que ella había presenciado, y que los festejadores de hoy no serían lo suficientemente fuertes o no sabrían prepararse lo necesario como para jugar al modo antiguo. Incluso agregó: “Ah... si el tiempo volviera atrás, nadie más jugaría maracatú”. A ese tipo de comentario, personas más jóvenes como Derivan suelen responder con cierta tranquilidad: "Si se pudiera volver en el tiempo, yo no jugaría”.

Uno de los temas predilectos durante las conversaciones que presencié en mi trabajo de campo era el de las innumerables historias acerca de la violencia del maracatú y de cómo, en ocasiones, esa violencia traía en su rastro la muerte. El tiempo en que esto ocurría puede ser entendido de diversas maneras. En las etnografías, es ocasionalmente abordado como la época en la cual el juego estaba supuestamente más ligado a una idea de sacralización o en la que los maracatús no se habían desplazado del contexto rural al urbano, ni habían comenzado a participar de los carnavales oficiales de Recife (ver Sena 2012; Vieira 2003).

Entre los festejadores hay otras consideraciones sobre lo que era el maracatú en ese tiempo antiguo. Particularmente, suelen hacer referencia constante a una época de desafíos y conflictos, de fuerzas difícilmente controlables. De ese tiempo se destaca que el maracatú era la práctica de cabocos que andaban sin destino fijo en pequeños bandos, o incluso solos, golpeando sus zurrones entre los cañaduzales e ingenios. En ese sentido, "ni existía el maracatú”, si se entendía como un conjunto de figuras vestidas por festejadores y allegados unidos bajo un 
nombre ${ }^{13}$. Al no haber grupos de maracatú, no existían tampoco las estratificaciones actuales en tipos de figuras. Por lo tanto, no había "ni caboco ni maestro caboco. Entraba quien quería. No había burra, ni catita, ni mateus ni nada. Había personas que andaban sueltas. El maracatú más grande tenía doce. No había rey, reina, ni dama; era solo caboco”, como explicó don Ramiro (2017).

Además de esto, en el tiempo antiguo no existía la posibilidad de que el maracatú o el caboco fueran bonitos, característica que sí tiene el maracatú de hoy, que invierte bastante en los disfraces, ropas y accesorios. Más que desfilar mostrando su belleza en las ciudades, el objetivo de un antiguo caboco era “andar por el mundo". Sobre ese contraste, don Ramiro cuenta que "hoy es todo belleza y hay caboco que no aguanta” y añade que "[él] no iba a presentarse en la calle, sino solamente a jugar”.

"Solamente a jugar" condensa, sin simplificar, lo que ocurría. En suma, como vimos, el maracatú consistía en cabocos que andaban en bandos entre los ingenios y cañaduzales sin destino cierto. Y, principalmente, el hábito de jugar sin disfraces parece haber sido más generalizado durante el tiempo antiguo, según dijo don Ramiro: "Antiguamente, caboco no jugaba disfrazado; era la manera en que se estaba aquí: usted iba y era caboco". Sobre esos cabocos -y sobre el maracatú en general- del tiempo antiguo, podríamos resumir con una expresión que es frecuentemente utilizada por los festejadores - pero también en Condado-: el desmantelo (desmantelamiento). Como nota Acselrad (2013), en el cavalo marim el desmantelo es una categoría estética referente a todo aquello que, en la vida o en el juego, es o está desordenado, feo, en oposición a lo cuidado, lo bello y la consonancia.

Ese desmantelo adquiere contornos específicos en el maracatú, y no por ser opuesto a la consonancia debemos descartarlo como algo necesariamente negativo o no deseado en el juego. Yo diría que el desmantelo caracteriza bien al tiempo antiguo por una razón: cuando existían disfraces, eran feos. Los cabocos andaban por el mundo enfrentándose. Las personas no tenían tanto "gusto y voluntad" como hoy; andaban a pie o colgados en tractores durante días; comían lo que fuera, lo que consiguieran en el momento. Había una especie de ecuación según la cual mientras más se estaba involucrado en el maracatú, menos apego se tenía al dinero y a los bienes materiales, y el juego era el foco de la vida de un festejador. Finalmente, son frecuentes los relatos sobre festejadores que, como

13 Esta cristalización del maracatú como un conjunto de figuras en series bien definidas es reciente y, puede decirse, contextual. Es posible localizar su establecimiento más consolidado a partir de la participación del maracatú en los concursos de carnaval organizados en Recife. Esa constitución de grupo es más visible en el periodo carnavalesco, en contraste con otros momentos del año. 
vimos, al salir como cabocos durante el carnaval, olvidaban a la familia y desconocían a los parientes.

Todavía ese tiempo es pensado como el de mayor fuerza. Los festejadores suelen evocarlo, tal como doña Bibi, para contrastar lo que ven hoy, criticando el hecho de que el juego se hubiera folclorizado o elogiando la belleza que adquirió a lo largo del tiempo. De todos modos, el consenso es que aquello que lo constituía ya no lo constituye más. De eso no deriva una nostalgia compartida, como vimos en el argumento de Derivan que, aunque reconoce y elogia la fuerza del tiempo antiguo, niega — como muchos otros — tener deseos de retornar a esa época.

Pero hay más. "En aquel tiempo, lo malo es que había cabocos buenos”, me dijo cierta vez don Ramiro. Entonces, a pesar de reunir tantos trazos y características que podríamos considerar negativos, el desmantelo del tiempo antiguo expresa, sobre todo, la cualidad de aquel juego y de sus festejadores. No obstante, hay algunas personas en Condado señaladas como desmanteladas: son extremadamente bravas, rápidas y habilidosas, además de andar “desarregladas” en lo cotidiano. En el maracatú, esas mismas personas son señaladas como festejadores excepcionales. Sin embargo, en lugar de elogios sobre túnicas y disfraces, como es común con buena parte de los festejadores, la excepcionalidad señalada se basa en la ferocidad y en las bellas y hábiles maniobras que ejecutan.

Nótese que esos festejadores desmantelados raramente participan de algún grupo. Al contrario, suelen hacer sonar el zurrón solitariamente durante el carnaval o en Semana Santa, y hacen apariciones esporádicas en ensayos y sambadas donde son efusivamente admirados y respetados. Mientras tanto, esas mismas personas son desmanteladas en el día a día y, por lo tanto, temidas o, al menos, tratadas con cautela. Si hubo un tiempo en que ser caboco era una condición dada (“Tal como usted está aquí, usted iba y era caboco”), es como si los festejadores desmantelados de hoy efectivamente hicieran concretas las formas de ser caboco del tiempo antiguo. La diferencia es que los sentimientos relativos a esas personas son ambiguos, porque regresar al tiempo antiguo implica regresar a ser el caboco que "andaba por el mundo" y a los peligros que esto suponía.

La admiración y el temor simultáneos indican que, aunque sea arriesgado, el desmantelo no puede ser del todo descartado. Y más que la posibilidad de regreso al pasado, parece haber una necesidad de volver o ansiar el retorno de ese tiempo. Es como si mantener su presencia fuera condición para que el maracatú pudiera efectuarse integralmente. Por otro lado, se busca que el tiempo antiguo aparezca apenas tangencialmente en el presente: no como un trazo histórico o como una versión más débil de lo que ya fue, sino como una fuerza, una intensidad experimentada por los festejadores o, incluso, como una parte o un destello de las potencias, poderes y fuerzas que permeaban el juego antiguamente. 
Fabio, uno de los principales festejadores de Leão, es enfático al decir que no es cualquier persona la que juega maracatú. De esta forma, más que delimitar un grupo específico para excluir a quienes no pueden jugar, él parece indicar que aquellos que lo hacen poseen una capacidad específica. Hay quienes de vez en cuando entran en algún grupo en el carnaval: de ellos se puede decir que "salen” en el maracatú. Esto, evidentemente, implica una disposición física y afectiva considerable. Pero hay quienes tienen una relación más íntima con el juego que se revela, por ejemplo, en la asiduidad de sus salidas, el hecho de poseer sus propios disfraces y, normalmente, tener lugares garantizados en un grupo. Esos son los llamados festejadores: aquellos que juegan maracatú y que son diferentes a quienes apenas “salen”.

Pero entre los festejadores hay quienes golpean su zurrón solitariamente durante el carnaval, o quienes no salen vestidos de caboco y se limitan a participar en algunas sambadas en el año - a veces incluso solo como espectadores-. Así, como vimos, no son apenas la adhesión a un grupo, la frecuencia de la participación o la atención a algún protocolo de la performance lo que garantiza que alguien sea un festejador. Se trata de algo más. Ciertos cabocos de la región son conocidos como muy temerarios por entrar y provocar enfrentamientos. Sin embargo, la cualidad de un buen festejador no se les atribuye a los más violentos, bravos o agresivos. Un buen festejador es aquel del cual reconocemos la capacidad de hacer todo esto, pero que opta por expresar su poder de otras maneras.

Me parece que la "gracia del juego", como dicen, está ahí: los "grandes” no son aquellos de los cuales se conocen todas las capacidades, habilidades y conocimientos, sino aquellos cuyas potencias apenas se vislumbran. Así, jugar implica la intensidad apropiada para mantener la continuidad y el éxito del maracatú y de sus festejadores, lo que, a su vez, supone la tensión de estar siempre muy próximo al límite, pero sin poder atravesarlo. Por lo tanto, jugar no podría ser una acción más seria: cuando un festejador deja de jugar es porque perdió su habilidad para lidiar con esas intensidades y fuerzas, o porque, siendo totalmente tomado por ellas, atravesó lo liminal del tiempo antiguo y simplemente se desmanteló. 


\section{Referencias}

Acselrad, Maria. 2013. Viva a pareia! Corpo, dança e brincadeira no Cavalo-Marinho de Pernambuco. Recife: Editora Universitaria UFPE.

—. 2019. "Dançando contra o Estado: a relação dança e guerra nas manobras dos caboclinhos de Goiana/Pernambuco”. Tesis doctoral en Antropología y Sociología, Programa de Posgrado en Antropología y Sociología, Universidade Federal do Rio de Janeiro, Río de Janeiro.

Amoras de Morais e Silva, Noshua. 2015. "Manobras e evoluções: etnografia dos movimentos do Maracatu Leão de Ouro de Condado”. Monografía de grado en Ciencias Sociales / Antropología, Departamento de Antropología, Universidade de Brasília, Brasilia.

—. 2018. “Composição e metamorfose no maracatu da Mata Norte de Pernambuco". Tesis de maestría en Antropología, Programa de Posgrado en Antropología y Sociología, Museu Nacional, Universidade Federal do Rio de Janeiro, Río de Janeiro.

Assis, Maria Elisabeth Arruda de. 1997. "Cruzeiro do forte a brincadeira e o jogo de identidade em um Maracatu Rural”. Tesis de maestría en Antropología, Programa de Posgrado en Antropología, Universidade Federal de Pernambuco, Recife.

Bastide, Roger. 1945. Imagens do nordeste místico em branco e preto. Río de Janeiro: Cruzeiro.

Bonald Neto, Olimpio. 1991. “Os caboclos de lança - azougados guerreiros de Ogum”. En Antologia do Carnaval do Recife, organizado por Mário Souto Maior y Leonardo Dantas Silva, 279-295. Recife: Fundação Joaquim Nabuco, Massangana.

Estrada, Christopher. 2015. "Caboclos of Nazareth: improvisations and renovation in Maracatu de Baque Solto of Pernambuco”. Tesis doctoral en Antropología e Historia, University of Michigan.

Ferreira, Ascenço. 1951. "O Maracatu”. En É de Tororó Maracatu Coleção Danças Pernambucanas, organizado por Hermilo Borba Filho, s. p. Río de Janeiro: Livraria-Editora da Casa do Estudante do Brasil.

Freyre, Gilberto. 1968. Guia prático, histórico e sentimental da cidade do Recife. Recife: José Olympio.

Garrabé, Lauré. 2010. "Les rythmes d’une culture populaire: les politiques du sensible dans le maracatu-de-baque-solto, Pernambuco, Brésil”. Tesis doctoral, Doctorado en Estética, Ciencias y Tecnologías de las Artes (Estudios Teatrales), Université Paris 8, Vincennes Saint Denis, Saint Denis.

Medeiros, Roseana Borges de. 2005. Maracatu rural: luta de classes ou espetáculos? Recife: Fundação de Cultura da Cidade do Recife.

Mello, Cecília Campello do Amaral. 2020. "Aquém da possessão: a noção de irradiação nos estudos de religião de matriz africana”. Anuário Antropológico 45 (2): 146-163. https://doi. org/10.4000/aa.5861

Murphy, John Patrick. 2008. Cavalo-Marinho pernambucano. Traducción de André de Paula Bueno. Belo Horizonte: UFMG. 
Oliveira, Valdemar de. 1948. “Indecifráveis Tuchauás”. Contraponto 7. s. d.

Omim Arruda de Castro Chaves, Suiá. 2008. "Carnaval em terras de caboclo: uma etnografia sobre Maracatus de Baque Solto”. Tesis de maestría en Antropología, Programa de Posgrado en Antropología y Sociología, Museu Nacional, Universidade Federal do Rio de Janeiro, Río de Janeiro.

Real, Katarina. 1967. O folclore no carnaval do Recife. Recife: Fundação Joaquim Nabuco, Massangana.

Sena, José Roberto Feitosa de. 2012. "Maracatus Rurais de Recife: entre a religiosidade popular e o espetáculo”. Tesis de maestría en Ciencias de la Religión, Programa de Posgrado en Ciencias de las Religiones, Universidade Federal da Paraíba, João Pessoa.

Silva, Anderson Vicente da. 2016. "Travestilidade masculina no Maracatu Rural pernambucano: gênero, ritual e performance em Nazaré da Mata/PE”. Tesis de doctorado en Antropología, Programa de Posgrado en Antropología, Universidade Federal de Pernambuco, Recife.

Silva, Severino Vicente da. 2005. Festa de caboclo. Coleção Maracatu e Maracatuzeiros, vol. 1. Recife: Associação Reviva.

Strathern, Marilyn. 2013. "Feathers and shells: learning to see. Lectures given in the Department of Social Anthropology, Cambridge University, Master Class”. HAU 2: 21-53.

Teixeira, Raquel Dias. 2013. "A poética do Cavalo-Marinho: brincadeira-ritual na Zona da Mata de Pernambuco”. Tesis de Maestría en Ciencias Sociales, Programa de Posgrado en Ciencias Sociales, Desarrollo, Agricultura y Sociedad, Universidade Federal Rural do Rio de Janeiro, Río de Janeiro.

—. 2016. "Cuidado e proteção em brinquedos de cavalo-marinho e maracatu da Zona da Mata Pernambucana”. Anuário Antropológico 41: 77-94. https://doi.org/10.4000/aa.2150

Tenderini, Helena Maria Ferreira da Silva. 2003. "Na pisada do galope Cavalo Marinho na fronteira traçada entre brincadeira e realidade”. Tesis de maestría en Antropología, Programa de Posgrado en Antropología, Universidade Federal de Pernambuco, Recife.

Vieira, Sévia Sumaia. 2003. "Dos canaviais à capital: cabocarias de flecha, maracatus de orquestra, baque solto, rural”. Tesis de maestría en Antropología, Programa de Posgrado en Antropología, Universidade Federal de Pernambuco, Recife.

-. 2012. “'O caboco velho, antigo, sabe brincar. Vai respeitar!': a diversidade dos rituais espirituais na brincadeira do Maracatu de Baque solto/rural”. Itacoatiara 2 (1): 62-75. https:// issuu.com/revista_itacoatiara/docs/itacoatiara_vol.2_n.1

Wagner, Roy. 1972. The innovation of meaning in Daribi religion. Chicago: University of Chicago Press. 